\title{
A Study on American Individualistic Values from the Movie the Pursuit of
}

\section{Happiness}

\author{
Lv Yingli, Guo Rui, Li Xuewei \\ Beijing City University, Beijing , China
}

Key Words: The Pursuit of Happiness, Individualism, Values

\begin{abstract}
In the filmThe Pursuit of Happiness, Gardner's life experience is a good interpretation of the core values of American culture - American individualistic values.Mainly from the independence, respect for others, individual struggles andthe sense of responsibility,this paper interpretedindividualistic values.
\end{abstract}

\section{Introduction}

The Pursuit of Happiness is a 2006 American biographical drama film based on entrepreneur Chris Gardner's nearly one-year struggle being homeless. Directed by Gabriele Muccino, the film featured Will Smith as Gardner, a homeless salesman. Will Smith and his son indeed performed the story. Through the film The Pursuit of Happiness, you can further understand the American individualism and American individualistic values. Individualism is the core of American culture, which is deeply rooted in the history of the United States. People believe that everyone has value, a high degree of personal freedom, the individual'sself-domination, self-control, self-development.The individualism which has shown in such an inspirational movie gives people enlightenment. As an artistic form of concentrated reflection to the culture, movies can reflect the patterns of country most intuitively.

\section{Literature Review}

Michael Prosser said, "Value is a major mode framed by cultural communications among individuals or groups, representing the deep-seated cultures. We believe that all people have their own values". Clyde Kluck-hohn suggested that the values "refer to the dominant or recessive concepts preferable for individuals or groups, influencing the people to make a choice out of all existing modes, ways and purposes of actions". It is observed that the values refer to the assessment and cognition of people on objective things, reflecting the value orientation and pursuit of people. Specifically, the values are reflected in the value objectives, value dimensions and certain standards, with which people judge the value of things.

Covering every aspect of social life, the values guide the social thoughts and behaviors of people. Unlike the vast majority of countries in the world, America is a multiracial nation of immigrants. The biggest feature is the ethnic diversity. Such a nation consisting of the people of different races, colors and ethnic groups creates unique values. As a large number of immigrants crowd into this "land of opportunities", the Americans have developed six basic values gradually, which not only influence every aspect of their lives but also get rooted in the sectors of American society, i.e., politics, economy, family, education, entertainment, work and religion. The three mainstream values include individual freedom, equal opportunity and material wealth. The individual freedom seems particularly important in the American value system. It is the most basic value of the Americans, 
and also the most sacred and most inviolable wording. Hence, America is also called as the "land of freedom”.

The individualistic values are both the core and spirit of American cultures. In the 1740s, Alexis de Toc-queville, the famous French politician and ideologist first used the word of "individualism" to summarize the American core values in his book Democracy in America. The introduction of Toc-queville and other western famous ideologists to the individualism apparently revealed that the individualism not only the mainstream of American values but also a type of value system, including the following three contents: firstly, individualism suggests that the personal interest should be supreme, and independent individuals, as the foundations of a society, a country and a collective, realize their individual purposes via the society, the collective, the nation and others; secondly, individualism politically attaches much importance to democracy, freedom and equality of individuals, and the personal powers should not be interfered or controlled by any societyand nation; thirdly, in the field of economy, individualism safeguards the private property system of individuals, supports and carries out the bourgeois private ownership, and no personal property may be invaded and controlled by any society and nation. The American individualistic values have an influence on the Americans in the sectors of economy, politics and spirit, and dominate the thinking modes, behavioral patterns and lifestyles of the Americans. Hence, the American individualistic values serve as the guiding thought of the American society, and also the core of American values.

For the Americans, freedom means controlling their own destiny with their best efforts and unyielding will, and being free from the interference of any other persons, including government and arbitrary power. The Americans attach great importance to ego and independence. They are fully aware that they must and can only achieve success for themselves, and they will not anchor their hopes to the society, the nation, the collective and any other persons. Their success is surely dependent on their own efforts.

\section{An Analysis of American Individualistic Values from the Movie The Pursuit of Happiness}

In The Pursuit of Happiness, the hero Chris who is brave, strong-minded and confident in face of predicaments, exactly manifests the American individualistic values. In the movie even thoughthe hero Chris met many difficulties in the life and work, he still kept optimistic, positive, and confident attitude, and this is precisely what individualistic values are. In broad terms, the American dream refers to the pursuit of freedom, democracy, equality; from narrow sense, it refers to the people in the United States rely on personal efforts to achieve their larger dreams in life, in other words, Americans can only rely on individual intelligence, perseverance in order to achieve the success, and any other person or organizations can't decide whether they will be successful or not. The United States is a relatively free country, and American people can only rely on their own strength to pursue happiness.

In pursuit of American dream, Americans are always self-independent. In American's eyes, only those who have achieved their American dream through self-reliance and efforts instead of network should be respected and praised.

The core thought of American individualistic values refers to the spirit of independence, that is, a person is encouraged to be independent, self-supporting and self-improved, and to create his/her own world through his/her efforts. The self-helping spirit is also another reflection of individualism in American cultures. Chris Gardner is independent. He took care of his little son by himself and did not need anybody's help, even his wife left them. The individualistic values in the film show the protagonist's independent ideas and the spirit of self-help. The core of American individualism values is the independent spirit. Spirit of self-help is also one of the concepts of individualism in 
American culture.In the movie, the actor's son, Christopher, told a story about God, revealing a principle: God helps those who help themselves. As the story read, a man who had fallen overboard struggled in water, but he didn't save himself but to sincerely pray, hoping Godto save him. A ship came over and lent a helping hand to him. He said God would save him, so he rejected; another ship came over again, but he still waited for God sincerely. Consequently, he was drowned. After arriving at the heaven, he questioned God: why didn't you save me? God answered, "I dispatched two ships to save you.” After laughing, we all understood the principle: God helps those who help themselves.

The American individualistic values are also reflected in the respect for others. Though Chris Gardner was facing so many challenges during his struggle, he still had very good attitude to his messy life. He didn't bow to the difficulties. Chris never complained about life.

In the movie, the leading actor's wife quarreled with him endlessly in the beginning, and afterwards they divorced because his wife could not bear the poverty. Chris always understood and respected the choice of his wife. However, with regard to the custody of his son, he insisted on living with him because he knew that a young black woman without good education and with sustenance problems could not take good care of his son. When the homeless father and son found a bed in an asylum ,the little son asked Chris, "Did mom leave because of me?" "Mother has her reason to leave and this is her own decision. This decision was with no relationship with others." Chris explained to his little son. Chris didn't blame his wife and didn't say anything bad of his wife to his little son. Chris not only guaranteed his son's physical safety, but also took care of the health of his son's mind.

Moreover, the protagonist did not treat his son's dependency on him as a subordinate; instead, he always considered his son as an independent individual. When they were homeless for the first time, they had to stay overnight in a bathroom of a subway station. To protect his son's self-esteem, he made up a story, imaging that they returned to the age of dinosaurs and thought the toilet as a "hole" in the shelter. The child was sleeping sedately in his father's arms. Furthermore, in a place nearby the basketball court, the protagonist discouraged his son's interest in the basketball unconsciously, but he was immediately aware of his mistake when seeing the depressing expression of his son. Then, he said to his son, “Don't ever let somebody tell you you can't do something, not even me. Don't ever say you can't do something or allow others to say so. Those who can't do something will often say so to you." Thus, it can be seen that, during the education of his son,Chris respected his choice and strove to foster his spirit of independence, instead of imposing his own desires on his son.

American individualistic values are also reflected in the course of personal struggles. In this aspect, the movie mainly manifests his optimistic and progressive attitude as well as his persistent endeavors in face of life. The most unforgettable scene in the movie is the running of the hero. His first running was to get the scanner taken by street performers. It was the one-month living costs of his family. For the second time, he took a taxi together with the investment manager in order to get a chance of interview, but he didn't have enough money to pay the taxi fee. So, he had to escape by running. For the third time, he was put into prison due to illegal car parking. On the morning of the second day, he left the police office with unkempt appearance, and rushed to a company for the interview; for the fourth time, he was driven out of the hotel during internship; besides, he had to run to the asylum for queuing as soon as possible every afternoon after work, so as to get a bed for his son. The whole movie reflects his pursuit to Happiness through running. The concept of "Pursuit of Happiness" always runs through the whole movie. This value could date back to the early days after the founding of America. On July 4, 1776, the Continental Congress adopted the Declaration 
of Independence drafted by Jefferson, proposing the following principles in the history of humans for the first time, "All men are born equal. The creator gives them certain inalienable rights, including the right of life, freedom and the right to pursue Happiness.” The movie interprets this principle based on the experience of Chris, that is, the right to pursue Happiness. Its significance means that a person can get happiness only through his/her unremitting efforts.

Setbacks are unavoidable in struggling, but the key is that we give up or forge ahead against hardships. The protagonist gave us a good answer. The movie depicted the image of an American civilian who still strove to make progress even when he was penniless andfrustrated. Despite the investment failure, leaving of his wife and friends, he didn't give up his dreams. Through a few years of efforts, he defeated other candidates with higher educational background in the capacity of a high school graduate, and did internship after passing the interview, taking the first step towards the success. However, this was only the beginning of his bad luck. Without salaries, he had to take his son to sell scanners here and there after work, so as to earn their bread. However, the fate decided. They could make ends after selling a few machines. As he forgot paying taxes, all his deposits were almost deducted by the government. He went bankrupt completely. On the other hand, he made the most of every minute at work in order to stand out of 20 interns and become a stockbroker of the security company. He never put down the telephone transmitter when making phone calls, so he could save eight minutes every day; besides, he didn't drink water all day long, so as to save the time for going to the lavatory. After work, he hurried to the asylum to queue for a bed. After he settled his son well, he read books under the light of sidewalk all night long, to enhance his professional ability. No matter what the terrible situation he would encounter, Chris was always optimistic and diligent because he firmly believed that happiness would arrive sooner or later as long as he persevered in his dream.

The film also expressedhis insistence on the dream, such as "If you have a dream, you have to guard it" (You have a dream, you got to protect it). "With the goal will go all out” (In particular, the word "Happyness" in the title is unique, and it implies a very important meaning in the film. In the film, Will Smith saw a word in the graffiti on the wall with spelling mistakes, he said this sentence: There is no reason inside Happiness, only me. (It's not H-A-P-P-Y-N-E-S-S. Happiness is spelled with an "I" instead of a "Y".)

At last, the American individualistic values are also reflected in the sense of responsibility for individuals, the society and family members. On the one hand, a person should be responsible for his own life; on the other hand, every person as a member of the society shall also be responsible for the society, his/her family and friends. In the movie, the protagonist Chris was responsible for his own life. Although his life was full of frustrations, he never gave up and did utmost to seek the path to happiness. When seeing everybody smiling happily after coming out of the stock exchange, he decided to be a security analyst, so as to change his life. He calmly analyzed his merits, numerical talents and communication skills. He never gave up even in face of his wife's cynical attitude and extremehardships in real life, and finally proved himself. Furthermore, due to his responsibility for his son, Chris could conquer such hostile environment and achieve success in his career. Chris had an unhappy childhood. He didn't see his father until he was 28 years old, so he always told himself that he would make his own child happy. With the attitude of being responsible for his son, Chris insisted on obtaining the guardianship of his son because he knew that his wife took better care of his son impossibly. When they became homeless and came to the mothers \& children relief station, he shouted, “No, I must be with my son”, after knowing his son could stay there only. It was exactly the responsibility that he could never give up under difficult conditions, and see hopes in desperation. 


\section{Conclusion}

The theme of the film is the pursuit of happiness, which is actually the interpretation and realization of American dream. In the United States, the individual is responsible for his own success and happiness. All the time, self-reliance and struggle are the symbol of American dream. In the real American life, there are so many people who have achieved success through self-reliance and struggle.The uniqueness of self-reliance and efforts can also be explained by citing one example in reality. For instance, when a Frenchmen and an American get laid -off, the Frenchman may blame the government while the American may blame himself for not working hard.

Ruth Benedict (1934) suggested in the book Patterns of Culture that the patterns of American cultures are composed of Christian traditions, republicanism and individualism. The core is the value of equality, freedom and personal struggles under the influence of Christian thought. As an artistic form of concentrated reflection to the culture, movies can reflect the patterns of host country most intuitively. The movie the Pursuit of Happiness is just such an excellent one, which makes audiences understand the values of American mainstream culture. This movie interprets the individualistic values of American culture mainly through the course of struggling of the protagonist Chris. It should be noted that theindividualism in the American cultures upholds freedom, independence and self-help, and highlights personal values and personal dignity, etc. The individualism in the American cultures is different from the so-called individualism under the cultural background of our collectivism. It is not a symbol of selfishness and parochialism.

After watching the movie, the audience can deeply feelhis happinessin the process of pursuing happiness. It was because of his relentless pursuit, so thehappiness finally embraced him. Happiness is not something that everyone has. As long as we believe in ourselves, andpersevere in the pursuit of happiness, the process of itself is happy.

\section{References}

[1] [US] Roland N. Stromberg. An Intellectual History of Modern Europe [M]. Translated by Liu Beicheng and Zhao Guoxin. Beijing: Central Compilation \& Translation Press, 2005.

[2] [US] Ruth Benedict. Patterns of Culture [M]. Translated by He Xizhang and Huang Huan. Beijing: SDX Joint Publishing Company, 1988. 